Fathers' Experiences in Caring for a Young Child with Autism Spectrum Disorder:

Recognising the "Forgotten Man"

\title{
Jessica Paynter*
}

AEIOU Foundation, PO Box 226, Nathan, QLD 4111 Australia; Telephone: +61 73212 1106; Email: jessica.paynter@aeiou.org.au

\section{Michael Davies}

School of Education and Professional Studies, Griffith University, Messines Ridge Road, Mt Gravatt, QLD 4122; Telephone: + 6173735 5623; Email: m.davies@griffith.edu.au

\section{Wendi Beamish}

School of Education and Professional Studies, Griffith University, Messines Ridge Road, Mt Gravatt, QLD 4122; Telephone: + 6173735 5636; Email: w.beamish@griffith.edu.au

*Corresponding author

\section{Acknowledgements}

We wish to thank the parents that participated in this research.

\section{Author Note}

This research did not receive any funding. There are no conflicts of interest to declare. 


\begin{abstract}

\section{Background}

Despite decades of research on family adaptation in relation to caring for a child with an Autism Spectrum Disorder (ASD), the wellbeing of fathers remains poorly understood.
\end{abstract}

\title{
Method
}

The present study sought to investigate experiences of fathers of young children with ASD aged between $2 \frac{1}{2} 2$ and 6 years attending an autism-specific early intervention centre. Eighteen fathers initially completed a mailed questionnaire and eight of these fathers were then interviewed by telephone. The questionnaire included standardised measures assessing constructs of the Double ABCX model of family adaptation. The interview used open-ended questions to understand the experiences of fathers' involvement in caring, sources of support, and coping strategies.

\section{Results}

Fathers experienced elevated levels of parental stress and elevated depressive symptoms. Interviews deepened understanding of fathers' personal experiences of each component of the Double ABCX model.

\section{Conclusions}

Limitations, directions for future research, and practical implications are discussed.

Keywords: Autism; fathers; family adaptation; wellbeing; Double ABCX model 
Recognising the "Forgotten Man”: Fathers' Experiences in Caring for a Young Child with Autism Spectrum Disorder

Parents of children with an Autism Spectrum Disorder (ASD) report significantly elevated levels of child and parent-related stress compared to parents of typically developing children (e.g., Baker-Ericzén, Brookman-Frazee, \& Stahmer, 2005; Lee, 2009). Emerging research suggests that fathers have distinct psychological profiles from mothers (Davis \& Carter, 2008), face unique challenges (Hastings, Kovshoff, Brown, et al., 2005), and make direct contributions to children’s development (Flippin \& Crais, 2011). However, despite decades of research into parental experiences of having a child with an ASD, the father remains the “forgotten man” (Eisenberg, 1957, p. 715). Most research has focused either exclusively or predominantly on mothers, with fathers significantly under-represented in research (see Braunstein, Peniston, Perelman, \& Cassano, 2013). As such, father’s unique experience of parenting remains poorly understood. Inquiry into fathers' experiences is vital, as it acknowledges the importance of the fathering role and enhances the understanding not only of their unique perspective, but also of the family unit as a whole. There is thus a need to specifically investigate fathers' experiences of caring for a young child with an ASD.

\section{Comparative Quantitative Studies}

An emerging body of literature compares experiences of mothers and fathers of children with ASD, with much of this research focussing on levels of stress (e.g., see Hayes \& Watson, 2013, for a review). These studies reveal challenges faced by parents of children with ASD such as a lack of “me time” (Ludlow, Skelly, \& Rohleder, 2012) and stress arising from reactions and judgements from others for their child's behaviour (Davis \& Carter, 2008; McStay, Trembath, \& Dissanayake, 2014). In addition, stress reported by fathers has generally been found to be lower than that reported by mothers (e.g., Dabrowska \& Pisula, 2010; Gray, 2003; Herring et al., 2006; Jones, Totsika, Hastings, \& Petalas, 2013; McStay, et 
al., 2014; Tehee, Honan, \& Hevey, 2009), although some studies report similar levels (Davis

\& Carter, 2008; Hastings, 2003; Hastings, Kovshoff, Ward, et al., 2005). This gender difference in stress levels has been explained in relation to mothers being, "typically more involved in the care of their children” (Jones et al., 2013, p. 2095) and fathers predominantly identifying with the "breadwinner" role in studies of fathers of children with disabilities (e.g., Towers \& Swift, 2006).

Although fathers' level of stress may be lower than that of mothers, they experience additional challenges compared to other fathers. For example, greater psychological distress is reported by fathers of children with ASD compared to fathers of children with other developmental delays (Herring et al., 2006) or who have typically-developing children (Baker-Ericzén, et al., 2005). Fathers of children with ASD may experience unique challenges compared to fathers of other groups of children; however, few studies have explored their experiences.

\section{Qualitative Studies}

A number of researchers have conducted qualitative studies on parents of children with ASD (e.g., Ludlow et al., 2012; Myers, Mackintosh, \& Goin-Kochel, 2009; Phelps, 2009). However, parental participation in many of these studies is dominated by mothers. Hence, differentiation or comparison between fathers and mothers is typically not possible.

Only a handful of researchers have conducted qualitative studies that have provided detailed information on fathers of children with ASD explicitly. Gray (2003) specifically investigated gender differences and found that the careers of fathers were routinely not restricted compared to those of mothers, with fathers reporting that their child's condition had limited impact on them personally. More specifically, Carpenter and Towers (2008) sought to understand the experiences of fathers of children with disabilities more broadly, including autism as well as other conditions, and reported fine-grained detail about stress, coping 
strategies, work, sources of support, and professional intervention. Taken together, these two studies provide a starting point for a deeper investigation into the lived experiences of fathers of children with ASD.

\section{The Double ABCX Model of Adaptation}

The use of established theoretical models of adaptation can assist in understanding the processes that may impact on fathers' wellbeing and burden. A number of researchers internationally (e.g., Hall \& Graff, 2011; Kaniel \& Siman-Tov, 2011; McStay, et al., 2014; Paynter, Riley, Beamish, Davies, \& Milford, 2013; Stuart \& McGrew, 2009; Pozo, Sarriá, \& Brioso, 2014) have applied variations of the Double ABCX model of family adaptation (McCubbin \& Patterson, 1983) as a framework to better understand the experiences of both mothers and fathers. These studies have found that the proposed model explains a significant proportion of the variance in adaptation for both mothers and fathers. Within this framework, adaptation describes the ability of the family to adjust and cope with change and/or stress (Olson, Sprenkle, \& Russell, 1979; Turnbull \& Turnbull, 2001). When applied to ASD, this model (see Figure 1) suggests that adaptation is affected by the severity of the initial stressor, in this case the child's ASD and behavioural symptoms, combined with additional pile-up of demands or stressors such as financial strain, consistent with the stress literature (e.g., Lazarus \& Folkman, 1984). Adaptation is then affected by the family and individual's resources including internal resources like self-esteem, and external resources like social support. It is further influenced by their response to the stressors and availability of effective coping strategies. Appraisals include the family’s positive and negative perceptions of having a child with ASD. Coping strategies refer to the strategies used by a family to manage stressors related to the child's ASD symptoms (see A in Figure 1), and the pile-up of demands (see aA in Figure 1).

[Figure 1 about here] 
In Australia, Paynter et al (2013) examined the experiences of 25 mothers and 18 fathers of children aged 2.5 to 6 years with ASD using the Double ABCX model. Consistent with previous international research (e.g., Pozo et al., 2014; Stuart \& McGrew, 2009) as well as recent Australian research (e.g., Mc Stay et al., 2014) they found support for the proposed relationships in the model with adaptation outcomes (individual, relationship, and family levels) significantly linked to children’s symptoms severity (challenging behaviour), accumulation of additional demands, the internal and external resources used to cope with these stressors, appraisals of stressors, and the use of particular coping styles (active avoidant linked to poorer outcomes). These findings however were collapsed across gender and the experiences of fathers specifically were not explored separately.

\section{Current Study}

Previous research has focused predominantly or exclusively on mothers. There is a clear need for further research with fathers explicitly to both value their unique role and perspective, and better understand the family as a whole. Recent quantitative research suggests the utility of the Double ABCX Model of family adaptation (McCubbin \& Patterson, 1983) in understanding variability in outcomes for both mothers and fathers, but has not been applied as a framework in qualitative studies to date. A recent study showed how this model provides a useful framework for understanding Australian families' adaptation to having a young child with ASD (Paynter et al., 2013), but did not discriminate fathers as a separate group. Thus, the aim of the present study was to explore fathers experiences in having a child with ASD and extend on the work by analysing fathers' data from Paynter et al (2013), and augmenting these findings with interview data from a subset of fathers who participated in the Paynter et al (2013) study using the Double ABCX model as a framework. To date, this is the first study to the authors' knowledge that has used mixed methods to understand fathers' experiences. We predicted fathers would describe roles that differed from their 
partners and would experience elevated psychological distress and parenting stress when compared to fathers of typically developing children. Drawing from the Double ABCX model, we expected fathers to share information on the impact of their child's behaviour and ASD symptoms, the pile-up of additional stressors, key internal and external resources and supports, and appraisals and coping strategies that led to their unique adaptive style. The key research question, therefore, that framed the present study was: "How well did the fathers responses align with the components of the Double ABCX model?”

\section{Materials and Methods}

\section{Setting}

This study was conducted within a not-for-profit organisation in Queensland that provides intensive early intervention within a full-time centre-based program for children from age 21/2 to 6 years who have been diagnosed with ASD (Paynter, Scott, Beamish, Duhig \& Heussler, 2012). The Foundation is a statewide service that provides intervention to approximately 200 children.

\section{Participants, Design, and Procedure}

Ethical approval was granted through the BLINDED. A mixed-methods design (Creswell, 2014) was used with quantitative questionnaire data and qualitative interview data being collected. Quantitative data were collected as part of a larger study on parental wellbeing that included both mothers and fathers (see Paynter et al., 2013). Eighteen fathers completed questionnaire measures as part of this larger study, a subset of eight fathers were subsequently interviewed by telephone. All participants received an information sheet that informed of the aims and purpose of the study, completion of the questionnaire was taken as consent for participation in this component. Interviewed fathers received an additional information sheet that outlined the aims and purpose of this component, and gave written 
informed consent for this component. All participants were assured that personal data would be kept confidential.

Demographic characteristics of participant fathers and their children are provided in Table 1. Questionnaire respondents had a mean age of 40.10 years, varied in work status, and the majority were married. The mean age of the fathers' children approximated 49 months, $72 \%$ of the children were males, and over $60 \%$ were diagnosed with Autistic Disorder. The subset of fathers who completed the interview appeared generally representative of the larger group in terms of employment status, age, relationship status, child gender, and diagnosis.

\section{[Table 1 about here]}

\section{Measures}

Quantitative measures. Questionnaire measures are listed in Table 2 and are described in detail in the larger study (see Paynter et al., 2013). In addition to these measures, a demographic questions were included to assess current characteristics of the family’s background, including ethnicity, household and social environment, as well as information about the child's diagnosis.

\section{[Table 2 about here]}

Qualitative measures. The qualitative measure was an in-depth, semi-structured telephone interview, with content adapted from Towers and Swift's (2006) study. Questions included ways in which fathers contribute to family life (responsibilities, roles, impact on family/relationship); impact on coping (e.g., support received); work (e.g., impact of having a child with ASD on work arrangements and capacity); and overall thoughts (e.g., experience of being a parent of a child with ASD). In addition, we asked fathers to reflect on the questionnaire results. For example, “The overall results suggest that fathers have elevated levels of stress and parenting stress. How true is this for you?" Interviews lasted approximately 60 minutes and were conducted via telephone by the second author who is a 
male psychologist with substantial experience working with families. The full interview guidelines are available from the authors. Interviews were recorded and transcribed verbatim.

\section{Data Analysis}

Quantitative data were analysed using PASW 18. Qualitative data were analysed using manual analysis guided by the Framework Approach (see Gale, Heath, Cameron, Rashid, \& Redwood, 2013) with the Double ABCX Model as an organising framework for analysis. First, categories (e.g., individual outcomes, external supports, and appraisals) from the Double ABCX model were used to drive matching and mapping of quotes from transcripts to develop a list of codes within these categories (e.g., within external support no family support/have family support). Second, initial codes were developed from the overall sense of the data and initial reading of manuscripts. Third, manual analysis involved the systematic examination of all eight transcripts and selection of quotes from each to sort into each category and code. Fourth, additional codes were added when data from a category did not fit an existing code. Throughout this process, coding categories were discussed among authors until consensus was achieved. Finally, a comparison was made between quantitative findings and qualitative themes and sub-themes identified within category codes. In reporting the results, data have been de-identified and representative quotes have been selected to illustrate key findings.

\section{Results}

\section{Overview of Fathers Interviewed and Roles}

Fathers interviewed all identified themselves as the biological fathers of their children and were living with their children at the time of interviews. Additional characteristics of each of these fathers are presented in Table 3. In interviews, fathers generally self-identified as the "breadwinner," or a variation on this such as "primary wage earner," or "primary 
money spinner" which they described as having the responsibility to earn sufficient money to support their family’s needs. For example, “I need to earn money so we can have a roof over our heads.” One father reported that "I do everything” following the death of his partner, and one reported that they "role swap...I have become the primary carer." Many saw their role as "helping” their partners with housework and child-rearing, with a number of fathers commenting that in terms of fathering they were often involved in "a lot of playing." Fathers who identified their partner as the primary caregiver reported their partner's role included organising appointments, liaising with services/funding, school drop-offs and pick-ups (with one exception reporting he does this), house work, and gathering information. Interestingly, the father who reported swapping roles, also reported his wife tended to be the one to seek out information ("I've got a wife that is a fabulous researcher"). About half the fathers reported worries of the burden of caregiving on their partner, for example, "she has a lot of stress on her in dealing with the boys." Two fathers expressed that swapping roles would be difficult, if not impossible financially, expressing "I would love to do that...my income is probably higher than $\{$ wife's $\}$ would be...so if we did that it would take an income hit”

[Table 3 about here]

\section{Family Adaptation Outcomes (X)}

Individual mental health. Two measures of outcome were investigated, parenting stress (the stress associated with parenting), and psychological distress (general mood symptoms) including depression, anxiety, and stress. With respect to parenting stress, on average fathers $(M=115.53, S D=20.66)$ scored above the $99^{\text {th }}$ percentile compared to normative data, and the majority of individual fathers (17/18) scored in the high range on the PSI-SF (Abidin, 1995). With respect to psychological distress, fathers in the present study reported on average elevated levels of mild (general) stress $(M=16.59, S D=10.78)$ and depression symptoms $(M=12.00, S D=9.14)$ on the DASS-21 (Lovibond \& Lovibond, 
1995). Anxiety symptoms $(M=6.35, S D=7.56)$ were within the normal range on the

DASS-21. However, a number of individual fathers reported elevated symptoms of depression ( $n=12)$, anxiety $(n=5)$, and stress $(n=9)$ at or above the $78^{\text {th }}$ percentile on the DASS-21 (see Lovibond \& Lovibond, 1995).

In interviews, fathers discussed the emotional burden of parenting a child with ASD, and many commented on the burden of supporting the family financially while also being concerned with their partner coping with caregiving responsibilities. Almost a half of fathers identified the burden of worrying about their partner's well-being and the caregiving burden on her. Fathers also discussed not having enough time to look after themselves including both their mental and physical health. For example, “you know that you're physically breaking down...you just can't seem to function when you are running on broken sleep, or very little sleep at times”

Many fathers shared this sentiment, lamenting the lack of "me time” and a desire to have some time to themselves and that this was also a source of stress. For example, “I don't get any leisure time...I don't have any time for me"

Relationship Quality. In the questionnaire measure, fathers' average rating of marital satisfaction $(M=31.82, S D=8.10)$ was in the non-clinical range, and $76.5 \%(13 / 17)$ of individual fathers scored in the non-clinical range on the MSQ (Norton, 1983). In contrast, in interviews, fathers revealed the challenges raising a child with ASD brought to their relationship. Common themes included having “no time," “get(ting) through the day in parallel,” or "no focus on the relationship.” Fathers focussed much of their time and energy on their child with ASD, and for the majority of fathers, this resulted in limited attention or time for their relationship. A couple of fathers commented on the additional stress raising a child with ASD brought to their marriage. Comments included that raising a child with ASD had put "a hell of a lot more stress into...the marriage." Some fathers also discussed 
conflict that arose from caring for a child with ASD due to the stress arising from parenting, feeling like they were not trusted to care for their child with ASD, or feeling like their contribution was not valued, such as,

Sometimes if you get told that you are not doing anything, and that you are, it sort of does, it does tear you up a bit because, I don't know, from my end, I sort of feel like I am putting a lot of effort in

However, most fathers also identified that their partner was a significant source of support, as will be discussed later under social support.

Family wellbeing. No quantitative measures were completed by fathers regarding family wellbeing. Interview data revealed common themes of a lack of time, focus on the child with ASD, and limitations in what the family could do. For example,

everything is then focused around um, the child with ASD, so the other kids in the family, or the family unit then basically has to conform to the needs of, or the demands then of \{child with ASD\}... And we all have an element of I guess, sacrifice when it comes to that

Some fathers also commented on the impact on siblings and challenges of not giving sufficient time and attention to siblings. Additionally, some fathers commented on challenges in accessing “normal type of activities” as a family such as camping, eating out, or other leisure activities due to the needs of the child with ASD. A number of fathers also commented on the impact on their extended family and challenges with family members excluding them or not accepting their child's diagnosis.

\section{Links between Outcomes and Predictors}

Severity of stressors (A). Over half (10/18) of fathers’ questionnaire responses suggested their child showed clinically-significant challenging behaviour on the SDQ (above the 80th percentile; see Goodman, 1997). A few $(n=4)$ reported slightly raised, and a few ( $n$ =4) reported average levels of challenging behaviour compared to normative data.

Interviewed fathers commented on a range of challenging behaviours such as property 
destruction , uncontrollable behaviour, "beat up" other children, severe anxiety, and "poopainted.”

Some fathers discussed that challenging behaviours were socially isolating or stigmatising. For many it was the reaction or perceptions of others that brought challenges. For example, “You can feel the hate. You know people are just like, 'can't even control their child. What is wrong with you?", and another father commented, "You know that they don't mean to judge...but you can tell they are." One theme that emerged from was the difficulty for others to understand their child's behaviour or symptoms due to the lack of physical markers of disability. Comments included "they look at \{child $\}$ and say he looks fine to me" Further, one father who had both a child with a physical disability and ASD reflected that people were more understanding of his child with a physical disability saying,

Like if it's physical, it is obvious ...If you've got a child that is autistic, these are beautiful children...so you've got these really endearing looking children who are doing objectionable things, therefore the child is misbehaving, these parents are, you know, they're rubbish parents that, you know, don't know what they're doing

In terms of autism symptoms, fathers discussed challenges around a lack of fear/safety awareness, social understanding difficulties, and communication. Some discussed delays in adaptive behaviours such as toileting and getting dressed as being challenging. On the other hand, two fathers shared that seeing their child acquire skills and develop was a source of joy, for example "it can be the most amazing, um joy when you see him take a step forward."

Pile-up of stressors (aA). Fathers reported experiencing over seven stressors $(S D=$ 4.93) on average of a possible 50 items on the RSRRS (Hobson \& Delunas, 2001). The most common stressors reported included experiencing financial problems/difficulties (15/18), children developing behaviour or learning problems (14/18), and having a major disagreement with a boss or co-worker (7/18). Similarly, these same stressors were the ones rated as being experienced with the most distress on the RSRRS experiencing financial distress $(M=2.72, S D=1.71)$, child developing behaviour or learning difficulties $(M=2.44$, 
$S D=1.62)$, and having a major disagreement with a boss or co-worker $(M=1.22, S D=$ 1.77).

Consistent with the quantitative findings, fathers frequently discussed their child's diagnosis, financial challenges, and difficulties balancing work with time with their family as sources of stress. In general, fathers agreed that the pile-up of additional stressors led to more stress. Moreover, they identified financial pressure, concerns with their child's development or behaviour, and work pressures as main themes, that were broadly consistent with the quantitative data. The challenge of balancing demands of being a "breadwinner" with the fathering role was raised by many fathers, with one father suggesting he would like to swap roles but that this was not feasible financially. However, one stressor that was particularly salient throughout interviews, and was not captured in the questionnaire, was time, particularly in relation to balancing work and home responsibilities. It followed that many fathers identified time as a source of distress. For example, "one of the bugbears at the moment is there is just, you know not enough hours in the day."

Internal resources (B). Interestingly, even when asked directly, fathers did not tend to report on internal characteristics such as being protective or helpful in alleviating burden. Rather, fathers were more likely to discuss how internal characteristics such as being introverted, or having low social esteem, affected them negatively or held them back from accessing support. For example, “All my life I have sort of relied on myself and not really looked for emotional or, or, or whatever support from elsewhere.” Further, another father noted, " "I would say I have self-esteem issues. I would say that ah, some of the depression is from self-esteem issues”

External resources (bB). Father's reported differing levels of support from significant other, family, and friends on the MSPSS (Zimet et al., 1988), using a repeated measures ANOVA with a Greenhouse-Geisser correction, $F(1.13,18.05)=5.22, p=.03$. 
Post hoc tests revealed that fathers reported greater support from their significant other $(M=$ 20.24, $S D=4.91)$ than friends $(M=16.50, S D=6.63), p=.01$. No significant difference between support from significant other and family $(M=17.18, S D=7.30)$, was found, $p=$ .07 , although a trend towards greater support from significant other was observed.

Consistent with quantitative data, about half the fathers interviewed reported that their partner was their main or sole source of support. For example, "She’s it mate..." and "\{partner\} is my main support”, and, "I've got no-one in direct support of me, other than my wife, and that's what we've learnt to, you know, expect...”. Some commented on hoping to extend their social support in the future, such as “...we're hoping in the next couple of years we might... get a little bit of a social life and hahahah, sort of life...” In interviews, about half of fathers reported challenges with accessing friends or family for social support, while those who had access to these supports emphasised the value in having this access.

A number of fathers reported receiving no support from extended family, with some isolated due to moving to access services, or others finding their extended family unable or unwilling to offer support. One father recalls a family member providing child care once, and said,

...they didn't think they could um, be of any benefit to me in the future and they were really sorry and they were totally embarrassed but um, and they said, being honest as they drove away from our place it was like a weight was lifted off their shoulders.

Many discussed that they would like or would appreciate greater family support. One father commented, “...the best thing that a father could get would be, I would say family support...family support is where I see is the real difference in the families of kids with ASD...”. Those who received family support shared that this included support for childminding, therapies, time management, and helping to pay bills.

A number of fathers commented on having friends they could talk to socially, but less so about being a father or about having a child with ASD. For example, one described his 
support from a friend as follows, “...he is very supportive. Um, in a distant kind of way, cause, especially blokes, they don't really know what to say or do about...with an ASD kid...but you know he supports when he can, moral support anyway.” However, fathers reported valuing these friendships and enjoying the opportunity to, “...start talking about normal things...”

A number of fathers discussed the value of opportunities to talk informally with other fathers. Examples included “My Time” sessions (government-funded group), events organised through community organisations, and activities related to their early intervention service. The general view appeared to be that it was beneficial to talk to other men who were going through similar challenges and to see other dads with “...kids that weren't normal”, and not having to think " "Oh God, \{child with ASD\} is going to misbehave, because they are all misbehaving..” One father discussed initial guilt over using funding to spend time with other fathers in a "pub” ( “...when I first did it I felt guilty about it...”), and the value he, and other fathers derived from this experience, “...it's fantastic, it’s incredible... it is people that really do know what you are talking about, and really do understand it, and you can compare strategies, and you can talk about your relationship...it's very handy...”

Fathers raised a number of other formal supports that were not covered in the questionnaire. These included community organisations, workplace supports, and psychologists/counsellors. They tended to report that these were not particularly helpful. For example, they reported in terms of their wellbeing that their general practitioner was not helpful and some commented (when asked) that their child's early intervention service did not tend to ask about it. However, only one father expressed that this was something he would like. Mixed feelings were raised in this group regarding respite. One father spoke of the value of respite for his family and that it gave him two hours to spend with his wife once per week and that he appreciated this time. Another father expressed dissatisfaction with 
respite received, commenting, “...most of them are just half-wit nineteen-year-olds who just want some cash you know while they are working through uni...”

One key area of external support missing from the quantitative investigation was "work". With most fathers identifying as the "breadwinner," it is perhaps not surprising that many identified their workplace, bosses, or colleagues as being a source of external support. This included being able to talk to colleagues or their boss, providing flexibility or leave to support family needs around diagnosis, and allowing a change in roles to suit the family’s needs more. In contrast, a number of fathers reported that they were aware of flexible work arrangements but did not feel that was something they could really do in practice. For example, "I have a vague awareness of it [flexible work arrangements]....just because something is allowed doesn't mean that you can necessarily do it...” This sentiment was echoed by at least one other father, and a further father reported having to use annual leave rather than carer's leave to support their child's needs.

The interview also revealed challenges with accessing and building an external support network. One father commented that “...building a support circle externally, is something that is very, very challenging..." Half of those interviewed commented on ASD being socially-isolating either indirectly (e.g., “..it took us out of public for a while...”), or directly (e.g., through challenges with time, not being invited to events, etc.). In addition, fathers commented on feeling that formal services tended to focus on mothers, or did not tend to ask about their wellbeing, or scheduled events when they were working. Fathers also discussed that it was difficult to find time for external services, navigate some services although others were helpful, they found it difficult to "open up to other people”, and that staff were mainly female. For example, one father commented, “...just there is women everywhere, which is fine, except that you know, some things um, you would prefer to talk to a bloke about..." 
Appraisal strategies (C). Father interviews revealed a range of appraisals they made about caring for a child with ASD. Negative or challenging appraisals arose in some fathers when summing up the experience of having a child with ASD, as “It's very demanding and stressful,” and “...equate it to being um a fighter pilot in the Battle of Britain. Um, if you drop your attention for more than ten seconds you are bound to get something nasty." Others saw the positive in the challenges, for example, commenting that it was " $a$ challenge and a lesson in humanity”, “it's stressful. It's um, a little scary...It's ah, can be very frustrating. Um, it can be most amazing, um, joy when you see him take a step forward" and “it has definitely been trying but, but I love him, you know like I, I love it. I wouldn't, I wouldn't have anyone else."

Positive appraisals included that coping made them stronger and that a diagnosis was viewed as a positive. A number of fathers also spoke of “God moments” where they reported they were thankful their child was not more severely impaired, or that they lived in Australia with access to services. For example, “And we had a number of what we called our 'God moments' where we just looked at what other people are managing with 'God we've got nothing to complain about'...”.

Coping strategies (cC). Fathers reported using a range of coping strategies (active avoidance, problem-focussed, positive coping, and religious/denial) on the Brief Cope (Carver, 1997). A repeated measures ANOVA found a significant difference between the frequency of use of each, $F(1,16)=137.17, p<.001$. Fathers reported using problemfocussed coping the most $(M=15.77, S D=1.00)$, followed by active-avoidance $(M=15.77$, $S D=1.00)$, positive coping $(M=14.38, S D=.70)$, and rarely using religious/denial coping $(M=5.47, S D=.54)$. Post hoc analyses showed that problem-focussed coping was used significantly more than any other coping strategy (comparison with active-avoidance, $p=$ .002; positive coping, $p<.001$; religious/denial, $p<.001$ ). Active-avoidance coping was 
used significantly more than religious-denial coping $(p<.001)$, but it was used a similar amount to positive coping $(p=.16)$.

In interviews, fathers also reported a range of coping strategies including: adjusting expectations, avoidance, bottling it up, denial, participating in recreational activities (e.g., writing poetry, exercise, and patting the family dog), focussing on "menial” activities like chores or driving, “harden up and keep going,” crying, planning, self-talk, sitting down and relaxing, talking to people (friends and professionals), medication, and using respite. Fathers' reflections on the utility of these strategies suggested they felt "bottling it up" or avoiding situations could make them worse. A novel finding from the interviews was the guilt expressed by some fathers for having “me time,” yet this was also a very common thing fathers reported needing or wanting, in varying degrees. For example, one father reported what he would like was, "a bit more time out...yeah I think that would probably, again it sounds a bit selfish, but it's going to make you less stressed and happier, and then, you know, try and be a better father." In addition, some fathers expressed that they would like someone to talk to and that it would help if they already had a relationship. For example, "I think establishing the relationship prior to the event is what actually means that someone will actually make that call.”

\section{Discussion}

Most fathers in the present study identified themselves as the "breadwinner," in line with previous research (Towers \& Swift, 2006). However, although mothers were generally identified primary carers, consistent with previous literature (e.g., Jones et al., 2013), fathers also identified more flexible supportive roles. As predicted, the burden of supporting the family financially and emotionally was expressed in elevated levels of psychological distress (stress and depression) and parenting stress that are consistent with previous research (e.g., Hayes \& Watson, 2011). Paternal stress emanated from the challenges of raising a child with 
ASD including their behaviour, pile-up of additional stressors, and responses to these consistent with the Double ABCX model. These also impacted on the marital relationship that subsequently suffered from a lack of time and focus. Fathers in this study emphasised the needs and concerns of their partner and their children over and above their own needs. They frequently reported a lack of “me time,” which was also reported by Ludlow et al. (2012). In all, fathers' responses were seen to be aligned with all components of the Double ABCX model.

Consistent with the model, child ASD symptoms were described as a source of stress. In addition, paternal stress was experienced in terms of the critical and judging reaction of others to the challenging behaviour of their child with ASD when obvious indicators of disability were absent. This common finding is in line with other research (e.g., Davis \& Carter, 2008; McStay et al., 2014). Moreover, their child’s lack of awareness of fear/safety and of communication and social understanding was stressful to fathers. The pile-up of additional stressors (e.g., major disagreement with boss or colleague) was perceived to lead to additional stress, consistent with the stress literature (Lazarus \& Folkman, 1984) and previous research with the Double ABCX model (e.g., McStay et al., 2014; Paynter et al., 2013).

The current study also sheds some light on fathers' perspectives on their internal and external resources in managing challenges and resultant stressors. In contrast to mothers in other studies (Hall \& Graff, 2010), and predictions from the Double ABCX model, fathers only reflected on a lack of internal resources. However, fathers readily identified external resources , with support from partners being highly valued and often their sole or main source of support, consistent with previous research (e.g., Hall \& Graff, 2011). As raised by Carpenter and Towers (2008), this finding highlights the challenges for sole fathers. 
Outside of their partner, fathers in this study were generally not well supported. They expressed a desire for support from the extended family, although support was rarely provided when needed. Similarly, friends were valued, but not perceived as a supportive resource for the fathering role. However, fathers found talking with other fathers of children with ASD to be an experience of high value, a finding consistent with Carpenter and Towers (2008). In some instances, work colleagues were also deemed to be supportive. In contrast, formal supports were perceived by some fathers as inaccessible and/or gender biased toward the mother. This finding was consistent with Carpenter and Towers (2008, p. 121) report of fathers who "felt that practitioners focused on their wives at meetings". In addition, some fathers expressed the need for more people to talk to while others reported it as a coping strategy.

As reported in the initial study (Paynter et al., 2013), interviewed fathers reported a range of coping strategies. Consistent with previous research, active avoidance (e.g., avoiding problems) was seen as unhelpful (e.g., Pozo et al., 2014). Adjusting expectations was also reported and this strategy may link with the kinds of appraisals these fathers made. While fathers reported both negative and positive appraisals, what stood out was the use of appraisals as a coping mechanism, consistent with the hypothesised mediating effect proposed by the Double ABCX model. For example, “God moments,” where fathers were thankful their child or situation was not worse, may be seen as a form of reframing (i.e., restructuring the problem in a positive way), which has been found to be linked to better outcomes for mothers and fathers in previous research (e.g., Hastings, Kovshoff, Brown, et al., 2005).

Based on collected data, and specific suggestions provided by the fathers interviewed, a number of recommendations to better support fathers and families with young children with ASD are proposed. First, fathers need a more substantial social network outside of their 
romantic relationship to support them in their everyday experiences. They need to develop proactive strategies to connect with and elicit help from extended family, colleagues and friends. Specific support groups and meetings for fathers can provide the impetus to facilitate network development, and father-to-father sharing and empathy. Specific professional help can also assist those experiencing psychological distress and depressive symptoms. Second, professionals working with the family need to schedule important meetings and activities at times when fathers are readily available. Access and relevance are key criteria to boost father participation and engagement. Third, fathers need to ensure that they have some "me-time." Because the burden for families of young children with ASD is substantial and continuous, fathers need to feel supported and enabled to consciously set aside time and space to refresh and reenergise in order to sustain self and support their partners and the family as a whole.

\section{Limitations}

The present study results have limited generalisability due to the relatively homogenous sample in terms of ethnicity, race, and socioeconomic status, as well as the high level of autism-specific services families received by the family. The present study did not include any non-residential fathers, step-fathers, or adoptive fathers who may experience the fathering role differently to biological custodial fathers and may have additional challenges in building and accessing a support network. In addition, while the theoretical model helped to frame the analysis, investigation of themes outside of the model was limited, and further research utilising inductive analysis may elucidate additional themes.

\section{Conclusion}

This study provides a strong and positive contribution to our understanding of fathers through an integration of data from quantitative and qualitative sources. Questionnaire data from Phase 1 of the study (Paynter et al., 2013) validated the Double ABCX model. Interview data (Phase 2 of the study) not only enhances our understanding of the model but 
also chronicles additional fathers' viewpoints. Recommendations provide a stepping stone to ensure increased recognition of, and support for fathers. Additionally, further research opportunities can extend the findings from this study to provide a deeper understanding of the fathering role and the important contributions that fathers provide within the family of young children with ASD. Such research will ensure that fathers are no longer the "forgotten man" (Eisenberg, 1957, p. 715).

\section{References}

Abidin, R. R. (1995). Parenting Stress Index [Short Form]. Odessa, Florida: Psychological Assesment Resources Inc.

Baker-Ericzén, M. J., Brookman-Frazee, L., \& Stahmer, A. (2005). Stress levels and adaptability in parents of toddlers with and without autism spectrum disorders. Research and Practice for Persons with Severe Disabilities, 30, 194-204.

Braunstein, V. L., Peniston, N., Perelman, A., \& Cassano, M. C. (2013). The inclusion of fathers in investigations of autistic spectrum disorders. Research in Autism Spectrum Disorders, 7, 858-865. doi: http://dx.doi.org/10.1016/j.rasd.2013.03.005

Carpenter, B., \& Towers, C. (2008). Recognising fathers: the needs of fathers of children with disabilities. Support for Learning, 23, 118-125. doi: 10.1111/j.14679604.2008.00382.x

Carver, C. (1997). You want to measure coping but your protocol's too long: Consider the brief cope. International Journal of Behavioral Medicine, 4, 92-100. doi: 10.1207/s15327558ijbm0401_6

Creswell, J. W. (2014). Research design: Qualitative, quantitative, and mixed methods approaches. London: Sage. 
Dabrowska, A., \& Pisula, E. (2010). Parenting stress and coping styles in mothers and fathers of pre-school children with autism and Down syndrome. Journal of Intellectual Disability Research, 54, 266-280. doi: 10.1111/j.1365-2788.2010.01258.x

Davis, N., \& Carter, A. (2008). Parenting stress in mothers and fathers of toddlers with Autism Spectrum Disorders: Associations with child characteristics. Journal of Autism and Developmental Disorders, 38, 1278-1291. doi: 10.1007/s10803-0070512-z

Eisenberg, L. (1957). The fathers of autistic children. American Journal of Orthopsychiatry, 27, 715-724. doi: 10.1111/j.1939-0025.1957.tb05539.x

Flippin, M., \& Crais, E. R. (2011). The need for more effective father involvement in early autism intervention. Journal of Early Intervention, 33, 24-50. doi: $10.1177 / 1053815111400415$

Gale, N., Heath, G., Cameron, E., Rashid, S., \& Redwood, S. (2013). Using the framework method for the analysis of qualitative data in multi-disciplinary health research. BMC Medical Research Methodology, 13, 117.

Goodman, R. (1997). The Strengths and Difficulties Questionnaire: A research note. Journal of Child Psychology and Psychiatry, 38, 581-586.

Gray, D. E. (2003). Gender and coping: the parents of children with high functioning autism. Social Science \& Medicine, 56, 631-642. doi: Doi: 10.1016/s0277-9536(02)00059-x

Hall, H. R., \& Graff, J. C. (2011). The elationships among adaptive behaviors of children with Autism, family support, parenting stress, and coping. Issues in Comprehensive Pediatric Nursing, 34, 4-25. doi: doi:10.3109/01460862.2011.555270

Hastings, R. P. (2003). Child behaviour problems and partner mental health as correlates of stress in mothers and fathers of children with autism. Journal of Intellectual Disability Research, 47, 231-237. doi: 10.1046/j.1365-2788.2003.00485.x 
Hastings, R. P., Kovshoff, H., Brown, T., Ward, N. J., Espinosa, F. D., \& Remington, B. (2005). Coping strategies in mothers and fathers of preschool and school-age children with autism. Autism, 9, 377-391. doi: 10.1177/1362361305056078

Hastings, R. P., Kovshoff, H., Ward, N. J., Espinosa, F., Brown, T., \& Remington, B. (2005). Systems analysis of stress and positive perceptions in mothers and fathers of preschool children with Autism. Journal of Autism and Developmental Disorders, 35, 635-644. doi: 10.1007/s10803-005-0007-8

Hayes, S. A., \& Watson, S. L. (2013). The impact of parenting stress: A meta-analysis of studies comparing the experience of parenting stress in parents of children with and without autism spectrum disorder. Journal of Autism and Developmental Disorders, 43, 629-642. doi: 10.1007/s10803-012-1604-y

Herring, S., Gray, K., Taffe, J., Tonge, B., Sweeney, D., \& Einfeld, S. (2006). Behaviour and emotional problems in toddlers with pervasive developmental disorders and developmental delay: associations with parental mental health and family functioning. Journal of Intellectual Disability Research, 50, 874-882. doi: 10.1111/j.13652788.2006.00904.x

Hobson, C., \& Delunas, L. (2001). National norms and life-event frequencies for the Revised Social Readjustment Rating Scale. International Journal of Stress Management, 8, 299-314. doi: 10.1023/A:1017565632657

Jones, L., Totsika, V., Hastings, R., \& Petalas, M. (2013). Gender differences when parenting children with Autism Spectrum Disorders: A multilevel modeling approach. Journal of Autism and Developmental Disorders, 43, 2090-2098. doi: 10.1007/s10803-012$1756-9$ 
Kaniel, S., \& Siman-Tov, A. (2011). Comparison between mothers and fathers in coping with autistic children: A multivariate model. European Journal of Special Needs Education, 26, 479-493. doi: 10.1080/08856257.2011.597186

Lazarus, R. S., \& Folkman, S. (1984). Stress, Appraisal, and coping. New York: Springer.

Lee, G. (2009). Parents of children with high functioning Autism: How well do they cope and adjust? [10.1007/s10882-008-9128-2]. Journal of Developmental and Physical Disabilities, 21, 93-114.

Lovibond, S. H., \& Lovibond, P. F. (1995). Manual for the Depression Anxiety Stress Scales. (2nd. ed.) Sydney: Psychology Foundation.

Ludlow, A., Skelly, C., \& Rohleder, P. (2012). Challenges faced by parents of children diagnosed with autism spectrum disorder. Journal of Health Psychology, 17, 702-711. doi: $10.1177 / 1359105311422955$

McCubbin, H. I., \& Patterson, J. M. (1983). The family stress process - The double ABCX model of adjustment and adaptation. Marriage \& Family Review, 6, 7-37. doi: 10.1300/J002v06n01_02

McStay, R., Trembath, D., \& Dissanayake, C. (2014). Stress and family Quality of Life in parents of children with Autism Spectrum Disorder: Parent gender and the Double ABCX Model. Journal of Autism and Developmental Disorders, 1-18. doi: 10.1007/s10803-014-2178-7

Myers, B. J., Mackintosh, V. H., \& Goin-Kochel, R. P. (2009). "My greatest joy and my greatest heart ache:" Parents' own words on how having a child in the autism spectrum has affected their lives and their families' lives. Research in Autism Spectrum Disorders, 3, 670-684. doi: DOI: 10.1016/j.rasd.2009.01.004

Norton, R. (1983). Measuring marital quality: A critical look at the dependent variable. Journal of Marriage and Family, 45, 141-151. 
Olson, D. H., Sprenkle, D. H., \& Russell, C. S. (1979). Circumplex model of marital and family system: I. Cohesion and adaptability dimensions, family types, and clinical applications. Family Process, 18, 3-28.

Paynter, J., Riley, E., Beamish, W., Davies, M., \& Milford, T. (2013). The double ABCX model of family adaptation in families of a child with an autism spectrum disorder attending an Australian early intervention service. Research in Autism Spectrum Disorders, 7(10), 1183-1195. doi: http://dx.doi.org/10.1016/j.rasd.2013.07.006

Paynter, J., Scott, J., Beamish, W., Duhig, M., \& Heussler, H. (2012). A pilot study of the effects of an Australian centre-based early intervention program for children with autism. The Open Pediatric Medicine Journal, 6, 7-14. doi:

$10.2174 / 1874309901206010007$

Phelps, K. W., Hodgson, J. L., McCammon, S. L., \& Lamson, A. L. (2009). Caring for an individual with autism disorder: A qualitative analysis. Journal of Intellectual \& Developmental Disability, 34, 27-35. doi: 10.1080/13668250802690930

Pozo, P., Sarriá, E., \& Brioso, A. (2014). Family quality of life and psychological well-being in parents of children with autism spectrum disorders: aAdouble ABCX model. Journal of Intellectual Disability Research, 58, 442-458. doi: 10.1111/jir.12042

Stuart, M., \& McGrew, J. H. (2009). Caregiver burden after receiving a diagnosis of an autism spectrum disorder. Research in Autism Spectrum Disorders, 3, 86-97. doi: DOI: 10.1016/j.rasd.2008.04.006

Tehee, E., Honan, R., \& Hevey, D. (2009). Factors contributing to stress in parents of individuals with Autistic Spectrum Disorders. Journal of Applied Research in Intellectual Disabilities, 22, 34-42. doi: 10.1111/j.1468-3148.2008.00437.x 
Towers, C., \& Swift, P. (2006). Recognising fathers report. Retrieved 01/04/10, from http://www.learningdisabilities.org.uk/publications/?esctl544701_entryid5=15166\&q $=0 \%$ c $2 \%$ acfathers $\%$ c $2 \%$ ac

Turnbull, A. P., \& Turnbull, H. R. (2001). Families, professionals, and exceptionality: Collaborating for empowerment (4th ed.). Columbus, OH: Merrill.

Zimet, G. D., Dahlem, N. W., Zimet, S. G., \& Farley, G. K. (1988). The Multidimensional Scale of Perceived Social Support. Journal of Personality Assessment, 52, 30 - 41. 


\section{Tables}

Table 1

Demographic Characteristics of Fathers and Clinical and Demographic Characteristics of their Children with ASD

\begin{tabular}{|c|c|c|}
\hline Demographic Characteristic & $\begin{array}{l}\text { Questionnaire } \\
\quad(N=18)\end{array}$ & $\begin{array}{c}\text { Interviewed } \\
\quad(n=8)\end{array}$ \\
\hline \multicolumn{3}{|l|}{ Age of father(years) } \\
\hline Mean (SD) & $40.10(10.32)$ & $38.60(10.71)$ \\
\hline \multicolumn{3}{|l|}{ Work Status (\%) } \\
\hline Full time paid employment & 61.1 & 50.0 \\
\hline Self employed & 22.2 & 25.0 \\
\hline Out of work (currently looking) & 5.6 & 12.5 \\
\hline Full time home duties & 5.6 & 12.5 \\
\hline Retired & 5.6 & \\
\hline \multicolumn{3}{|l|}{ Relationship Status (\%) } \\
\hline Married & 77.8 & 62.5 \\
\hline Living with partner/de facto & 11.1 & 12.5 \\
\hline Widowed & 5.6 & 12.5 \\
\hline Separated & 5.6 & 12.5 \\
\hline \multicolumn{3}{|l|}{ Family total yearly income (\%) } \\
\hline$\$ 26,001$ to $\$ 34,000$ & 5.6 & 12.5 \\
\hline$\$ 34,000$ to $\$ 50,000$ & 16.7 & 25.0 \\
\hline$\$ 50,001$ to $\$ 80,000$ & 22.2 & 25.0 \\
\hline$\$ 80,001$ or more & 50.0 & 25.0 \\
\hline Negative income/loss & 5.6 & 12.5 \\
\hline \multicolumn{3}{|l|}{ Age of child (months) } \\
\hline Mean (SD) & $49.39(9.11)$ & $53.38(5.01)$ \\
\hline \multicolumn{3}{|l|}{ Gender of child (\%) } \\
\hline Female & 27.8 & 25.0 \\
\hline Male & 72.2 & 75.0 \\
\hline \multicolumn{3}{|l|}{ Diagnosis (\%) } \\
\hline Autistic Disorder & 61.1 & 62.5 \\
\hline Asperger's Disorder & 5.6 & 12.5 \\
\hline PDD-NOS & 5.6 & 12.5 \\
\hline Other e.g.,"ASD” & 27.8 & 12.5 \\
\hline
\end{tabular}


Table 2

Quantitative Measures

Domain

Measure

A. Severity of Symptoms

Challenging Behaviour

Australian parent-rated version of the Strengths and Difficulties Questionnaire (SDQ) 4-10 years version (Goodman, 1997)

aA. Pile-up of Stressors

Revised Social Readjustment Rating Scale (RSRRS: Hobson \& Delunas, 2001)

bB. External Resources

Multidimensional Scale of Perceived Social Support (MSPSS: Zimet, Dahlem, Zimet, \& Farley, 1988)

cC. Coping Strategies

$X$. Family Adaptation Outcomes

Parenting Stress

The Brief COPE (Carver, 1997)

Psychological distress

The Parenting Stress Index: Short Form (PSISF: Abidin, 1995)

Depression Anxiety Stress Scale- 21 (DASS-21: Lovibond \& Lovibond, 1995)

Relationship Quality

The Marital Satisfaction Questionnaire (MSQ:

Norton, 1983) 
Table 3

Overview of Interviewed Fathers

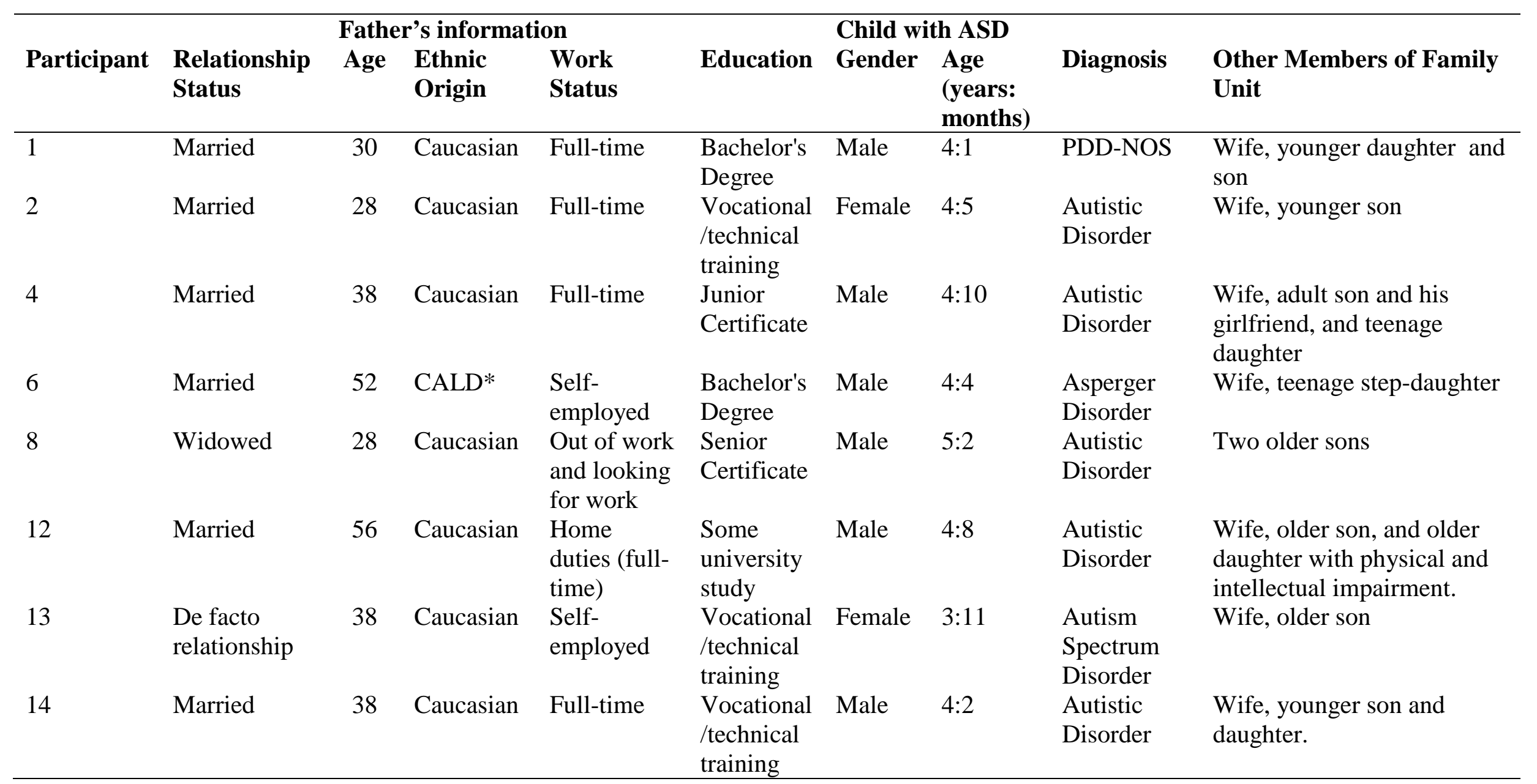

* Culturally and Linguistically Diverse background, specific ethnicity is not included to preserve confidentiality 


\section{Figure Caption}

Figure 1: Modified Double ABCX model (reproduced from Paynter et al., 2013) 